\title{
The Retinitis Pigmentosa 1 Protein Is a Photoreceptor Microtubule-Associated Protein
}

\author{
Qin Liu, ${ }^{1}$ Jian Zuo, ${ }^{2}$ and Eric A. Pierce ${ }^{1}$ \\ ${ }^{1}$ F. M. Kirby Center for Molecular Ophthalmology, Scheie Eye Institute, University of Pennsylvania School of Medicine, Philadelphia, Pennsylvania 19104, \\ and ${ }^{2}$ Department of Developmental Neurobiology, St. Jude Children's Research Hospital, Memphis, Tennessee 38105
}

The outer segments of rod and cone photoreceptor cells are highly specialized sensory cilia made up of hundreds of membrane discs stacked into an orderly array along the photoreceptor axoneme. It is not known how the alignment of the outer segment discs is controlled, although it has been suggested that the axoneme may play a role in this process. Mutations in the retinitis pigmentosa $1(R P 1)$ gene are a common cause of retinitis pigmentosa (RP). Disruption of the $R p 1$ gene in mice causes misorientation of outer segment discs, suggesting a role for RP1 in outer segment organization. Here, we show that the RP1 protein is part of the photoreceptor axoneme. Amino acids 28-228 of RP1, which share limited homology with the microtubule-binding domains of the neuronal microtubule-associated protein (MAP) doublecortin, mediate the interaction between RP1 and microtubules, indicating that the putative doublecortin (DCX) domains in RP1 are functional. The N-terminal portion of RP1 stimulates the formation of microtubules in vitro and stabilizes cytoplasmic microtubules in heterologous cells. Evaluation of photoreceptor axonemes from mice with targeted disruptions of the $R p 1$ gene shows that Rp1 proteins that contain the DCX domains also help control axoneme length and stability in vivo. These results demonstrate that RP1 is a MAP. Given the specific expression of RP1 in photoreceptors, RP1 is thus the first photoreceptor-specific MAP to be identified. Furthermore, these findings indicate that the RP1 form of inherited retinal degeneration is part of the larger class of neurodegenerative diseases caused by MAP dysfunction.

Key words: axoneme; cilia; microtubule-associated proteins; outer segment; photoreceptor; retinitis pigmentosa

\section{Introduction}

Mutations in the retinitis pigmentosa $1(R P 1)$ gene are a common cause of retinitis pigmentosa (RP), a common form of inherited blindness characterized by death of the photoreceptor cells of the retina (Pierce et al., 1999; Berson et al., 2001). As for most of the $100+$ identified retinal degeneration disease genes, the function of the RP1 protein in vision and the mechanism by which the identified mutations lead to photoreceptor cell death are not completely understood (Pierce, 2001; Pacione et al., 2003; RetNet, 2004).

The four-exon RP1 gene encodes a 2156 amino acid protein that is expressed exclusively in photoreceptor cells (Guillonneau et al., 1999; Pierce et al., 1999; Sullivan et al., 1999). The RP1 protein is located in the region of the connecting cilium and axoneme of photoreceptor cells (Liu et al., 2002). The "connecting cilium" is the small bridge that links the outer segment to the

\footnotetext{
Received April 8, 2004; revised June 7, 2004; accepted June 7, 2004.

This work was supported by National Institutes of Health Grants EY12910, EY12950, and CA21765, Research to Prevent Blindness, the Foundation Fighting Blindness, the Rosanne Silbermann Foundation, the F. M. Kirby Foundation, and the American Lebanese Syrian Associated Charities. We thank Sara Achenbach and Jason Skalet for their technical assistance, Dr. Qian-Chun Yu for his expert assistance with electron microscopy, the other members of the RP1 Consortium (Q.L., J.Z., and E.A.P. are members of the RP1 Consortium) for their encouragement, and Drs. Edward Pugh, Leonard Feiner, Greg Guild, and Erica Holzbauer for their critical comments on this manuscript.

Correspondence should be addressed to Dr. Eric A. Pierce, F. M. Kirby Center for Molecular Ophthalmology, University of Pennsylvania, 305 Stellar-Chance Laboratories, 422 Curie Boulevard, Philadelphia, PA 19104. E-mail: epierce@mail.med.upenn.edu.

DOI:10.1523/JNEUROSCI.1335-04.2004

Copyright $\odot 2004$ Society for Neuroscience $\quad$ 0270-6474/04/246427-10\$15.00/0
}

cell body of photoreceptors (see Fig. 1E). The outer segments of rod and cone photoreceptor cells are highly specialized sensory cilia, with hundreds of membrane discs stacked into an ordered array. Like other cilia, photoreceptor outer segments contain a microtubule-based axoneme, which begins at the basal body in the distal portion of the inner segment, passes through the connecting cilium, and continues into the outer segment for up to $80 \%$ of its length (Rohlich, 1975; Kaplan et al., 1987). Because the outer segment discs line up perfectly along the axoneme, it has been suggested that the axoneme may stabilize the stack of disc membranes (Kaplan et al., 1987). Despite this central role in photoreceptor biology, little is known about the axoneme and the factors that control its length and stability (Song and Dentler, 2001).

The phenotypes of two lines of mice with distinct targeted disruptions of the Rp1 gene suggest that RP1 participates in organizing outer segment discs. The Rp1-exon 2-3 deletion allele (designated herein as $\Delta 2-3$ ) was produced by removing exons 2 and 3 from the gene. An abnormal Rp1 protein that is lacking the $\mathrm{N}$-terminal 269 amino acids is produced in the retinas of $R p 1$ $\Delta 2-3$ mice (Gao et al., 2002). The Rp1-myc allele was generated by truncating the mouse $R p 1$ coding sequence to mimic the most common mutation (Arg677Ter) in RP1 (Liu et al., 2003). Both homozygous $R p 1^{\Delta 2-3 / \Delta 2-3}$ and $R p 1^{\text {myc/myc }}$ mice experience rapid retinal degeneration characterized by the accumulation of small packets of intact but incorrectly oriented discs in place of outer segments (Gao et al., 2002; Liu et al., 2003). 
Given the importance of microtubule-associated proteins (MAPs) in regulating microtubules, which in turn are responsible for determining cell shape, it has been suggested that MAPs associated with outer segments could play a role in controlling outer segment organization (Shichi, 1983). Exons 2 and 3 of RP1 (codons 1-262) share limited homology (31\%) with the microtubule-binding domains of doublecortin (DCX), a neuron-specific MAP that is required for neuronal migration during development (Francis et al., 1999; Gleeson et al., 1999). The location of RP1 in the region of the connecting cilium and axoneme of photoreceptors and the presence of the possible DCX domains in RP1 suggest that RP1 could be a MAP. To gain further insight into the function of the RP1 protein, we have refined the location of the protein in photoreceptors and investigated the function of the DCX domains in vitro and in vivo. Our results indicate that RP1 is a photoreceptor-specific MAP that participates in controlling the length and stability of the photoreceptor axoneme.

\section{Materials and Methods}

Animals. This research followed the University of Pennsylvania Guidelines for Animal Care and Use. Wild-type C57BL/6J mice were obtained from Jackson Laboratories (Bar Harbor, ME). The Rp1-myc mice were generated in our laboratory, and the $R p 1$-exon 2-3 deletion mice were obtained from Dr. Jian Zuo (Gao et al., 2002; Liu et al., 2003). Homozygous $R p 1^{\Delta 2-3 / \Delta 2-3}$ and $R p 1^{m y c / m y c}$ mice were crossed to generate the double mutant $R p 1^{m y c / \Delta 2-3}$ mice.

Immunofluorescence microscopy. Eyes from wild-type adult mice or 2-week-old double mutant $R p 1^{m y c / \Delta 2-3}$ mice were processed in two different ways for immunostaining experiments. For double immunostaining using anti-retinitis pigmentosa GTPase regulator (RPGR) antibodies, eyes were enucleated, snap-frozen, embedded in OCT without fixation, and cryosectioned at $10 \mu \mathrm{m}$. Sections were postfixed with $1 \%$ paraformaldehyde in PBS for 10 min before immunostaining was performed (Hong et al., 2003). For immunostaining using other antibodies, the eyes were enucleated after cardiac perfusion with $4 \%$ paraformaldehyde in PBS, $\mathrm{pH} 7.4$, and fixed in $4 \%$ paraformaldehyde for $3 \mathrm{hr}$, embedded in OCT freezing media, and cryosectioned at $10 \mu \mathrm{m}$. The frozen sections were then immunostained as described previously (Liu et al., 2002). The primary antibodies used were chicken polyclonal anti-C'-Rp1 (Liu et al., 2002), monoclonal anti-myc (Cell Signaling Technology, Beverly, MA), anti-acetylated $\alpha$-tubulin (clone 6-11B-1; Sigma, St. Louis, MO), antiRom1 (Rom 1D5; a gift from Dr. Robert Molday, University of British Columbia, Vancouver, Canada), rabbit polyclonal anti-RPGR, and antiRPGR interacting protein (RPGRIP) (gifts from Dr. Tiansen Li, Harvard University, Cambridge, MA). Cy3-, Alexa 468-, and Alexa 633conjugated secondary antibodies were obtained from Jackson ImmunoResearch (West Grove, PA) or Molecular Probes (Eugene, OR). Stained sections were viewed with a Zeiss LSM 510 Meta confocal microscope, and the images were processed with Zeiss Meta 510 software (Carl Zeiss MicroImaging, Thornwood, NY).

For measurement of axoneme length, $12-\mu \mathrm{m}$-thick frozen sections were stained with anti-acetylated $\alpha$-tubulin antibodies as described above. The stained sections were evaluated by confocal immunomicroscopy, and the cord lengths were measured using the Zeiss Meta 510 software.

Isolation of photoreceptor outer segments and axonemes. Individual photoreceptor outer segments were isolated using a modification of established techniques (Yang et al., 2002). Briefly, fresh wild-type retinas from 2 -week-old C57BL/6 mice were collected and fixed with 4\% PFA in PBS for $30 \mathrm{~min}$. The retinas were rinsed in PBS and then shaken gently in 100 $\mu l$ of PBS. Ten microliters of the resulting suspension, which contained intact outer segments, were transferred to a glass slide and coimmunostained with antibodies to Rp1 and acetylated $\alpha$-tubulin antibodies as described above.

A modification of this approach was used to isolate individual photoreceptor axonemes. Fresh retinas from at least three 2-week-old wild- type, homozygous $R p 1^{\Delta 2-3 / \Delta 2-3}$, and $R p 1^{m y c / m y c}$ mice were dissected and immediately frozen in liquid nitrogen. The frozen retinas were then thawed in $100 \mu \mathrm{l}$ of PBS and shaken gently. With this freeze-thaw approach, the major component present in the resulting suspension was individual axonemes. Ten microliters of the axoneme solution were used for immunostaining with anti-Rpl and $\alpha$-tubulin antibodies (clone DM1A; Sigma). The axonemes were viewed with confocal differential interference contrast (DIC) and fluorescence microscopy. Axoneme cord lengths were measured from the DIC images using the Zeiss Meta 510 software.

Electron microscopy. Eye cups from 2-week-old wild-type C57BL/6 mice were fixed in $0.05 \%$ glutaraldehyde plus $2 \%$ paraformaldehyde in PBS, $\mathrm{pH}$ 7.4, for $1 \mathrm{hr}$. Tissues were then dehydrated in a graded ethanol series, infiltrated, and embedded in EMbed812 (Electron Microscopy Sciences) or Lowicryl resin. For ultrastructural analyses, ultrathin sections $(70 \mathrm{~nm})$ were cut, stained with lead citrate and uranyl acetate, and examined using a Jeol 1010 transmission electron microscope. For immunoelectron microscopy, ultrathin sections of the Lowicryl-embedded tissue were collected on 200-mesh nickel grids coated with Formvar. The samples were blocked in 1\% BSA in PBS for $30 \mathrm{~min}$, followed by incubation with anti- $\mathrm{C}^{\prime}$-Rp1 antibody (1:400) in blocking buffer overnight at $4^{\circ} \mathrm{C}$. The sections were then washed, incubated with goat anti-chicken IgY conjugated to colloidal gold $(10 \mathrm{~nm}$ ) for $40 \mathrm{~min}$, stained with uranyl acetate, and examined.

Expression of human RP1 proteins in COS-7 cells. The full-length RP1 cDNA was amplified from total human retinal RNA by RT-PCR and cloned into the pcDNA3.1/V5-His vector (Invitrogen, Gaithersburg, $\mathrm{MD})$. Four cDNA fragments corresponding to codons 1-682 (N1), 238682 (N2), 704-1,812 (M), and 1,788-2,156 (C) of the human RP1 coding sequence (GenBank NM_006269) were then amplified by PCR from the full-length $R P 1 \mathrm{cDNA}$ clone using primers containing the desired restriction enzyme recognition sites and subcloned into pcDNA3.1/V5-His.

COS-7 cells were cultured on glass coverslips in six-well plates using DMEM media (Invitrogen) with 10\% fetal bovine serum (HyClone, Logan, UT) at $37^{\circ} \mathrm{C}$ with $10 \% \mathrm{CO}_{2}$. For expression experiments, $1-3 \mu \mathrm{g}$ of each RP1 construct was transfected into $1 \times 10^{5}$ cells using Lipofectamine 2000 (Invitrogen). After $48 \mathrm{hr}$, the transfected cells were washed twice with room temperature PBS and fixed with cold methanol for $2 \mathrm{~min}$. The cells were then permeabilized with $0.5 \%$ Triton X-100 in PBS for 10 min, blocked with $1 \%$ BSA and $0.2 \%$ Triton X-100 in PBS for $1 \mathrm{hr}$, and then incubated sequentially with monoclonal anti-V5 antibodies (Invitrogen), Cy3 goat anti-mouse antibodies (Jackson ImmunoResearch), and FITC-conjugated anti- $\alpha$ tubulin antibodies (clone DM1A; Sigma). Cell nuclei were counterstained with $4^{\prime}, 6^{\prime}$-diamidino-2phenylindole (DAPI) $(1 \mu \mathrm{g} / \mathrm{ml}$; Molecular Probes). Fluorescent signals were visualized using a Nikon TE300 fluorescent microscope or a Zeiss LSM 510 Meta confocal microscope. For the microtubule stability experiments, transfected cells were treated with $2.5,5$, or $10 \mu \mathrm{M}$ nocodazole for $2 \mathrm{hr}$ before being immunostained as described above.

Isolation of microtubules from retina. Microtubules were assembled from the cytosolic fraction of mouse retina as described (Weingarten et al., 1975; Gleeson et al., 1999). Briefly, retinas from wild-type C57BL/6 mice were homogenized in PEM buffer (80 mM HEPES, pH 7.5, $1 \mathrm{~mm}$ EGTA, and $2.5 \mathrm{~mm} \mathrm{MgCl}_{2}$ ) containing $0.5 \%$ Triton-X100 and $1 \times$ protease inhibitor mixture (Roche Applied Science, Indianapolis, IN). The homogenates were then centrifuged $100,000 \times g$ for $30 \mathrm{~min}$ at $4^{\circ} \mathrm{C}$, and the tubulin-rich cytosol was collected. Five milligrams of cytosol were then added to $500 \mu \mathrm{l}$ of PEM-GTP buffer plus $20 \mu \mathrm{M}$ Taxol, and the mixture was incubated at $35^{\circ} \mathrm{C}$ for $30 \mathrm{~min}$ to allow the microtubules to polymerize. The polymerized microtubules were then collected by centrifugation at $100,000 \times g$ for $40 \mathrm{~min}$ at $35^{\circ} \mathrm{C}$ through $1 \mathrm{ml}$ of cushion buffer (PEM buffer plus 20\% sucrose and $20 \mu \mathrm{M}$ Taxol). The supernatant from this initial spin was collected. The microtubule pellets were then subjected to three cycles of cold depolymerization, warm polymerization, and centrifugation. The final purified microtubule pellet, the concentrated supernatant, and an aliquot of the initial cytosol were then subjected to Western blotting with anti-Rp1 antibodies (Liu et al., 2002).

In vitro microtubule binding assay. For these experiments, cytosolic extracts were prepared from N1-RP1- and N2-RP1-transfected COS-7 

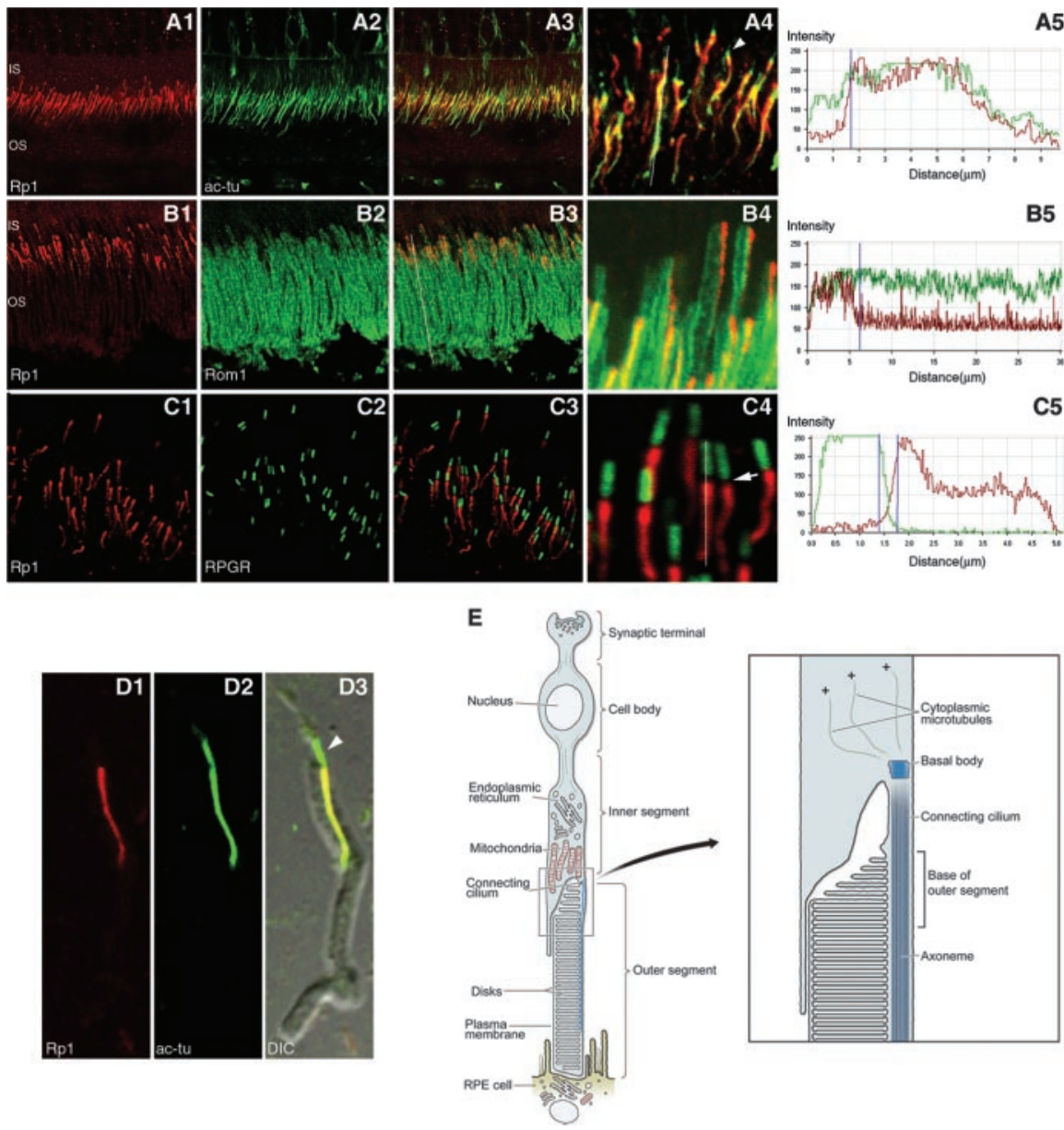

Figure 1. The RP1 protein is located in the outer segment portion of the photoreceptor axoneme. Frozen sections $(A-C)$ or isolated photoreceptor outer segments $(D)$ from adult $\mathrm{C} 57 \mathrm{BL} / 6$ mouse retinas were double immunostained with antibodies to Rp1 and acetylated $\alpha$-tubulin $(A, D), \operatorname{Rp} 1$ and Rom1 $(B)$, or Rp1 and RPGR ( $C$. The coimmunostained samples were viewed with a Zeiss LSM510 Meta confocal microscope. For $A-C$, separated images for the two labels are presented in columns 1 and 2. Merged images are shown in columns 3 and 4, with higher-magnification views in column 4 . Representative quantitative analyses of the immunostaining patterns are shown in column 5 . For these analyses, the intensity of the different fluorescent labels was evaluated in each pixel along a line drawn through the axoneme using the LSM 510 Meta analysis software (lines $A 4, B 3,(4)$ ). The separated signal intensities for each dye were plotted as a function of distance. $A, D$, The Rp1 protein colocalizes with the acetylated $\alpha$-tubulin-labeled axoneme in the outer segment but not in the connecting cilium, as indicated by the green signal that extends above the outer segment into the connecting cilium ( $A 4, D 3$, arrowheads). $B$, Rp1 is located in the proximal portion of outer segments, as indicated by the colocalization of the Rp1 and Rom1 signals. C, The Rp1 signal does not overlap with the RPGR signal in the connecting cilium, but rather there is a gap between the two signals ( 4 , arrow). E, Diagram of rod photoreceptor cell. The region of the connecting cilium and the base of the outer segment are enlarged on the right to show the axoneme in the connecting cilium and outer segment. This ophthalmic orientation, with the outer segments of the photoreceptors pointing down, is used in all the figures. IS, Inner segment; OS, outer segment; ac-tu, acetylated $\alpha$-tubulin.

cells as described above. Microtubules were assembled from $100 \mu \mathrm{g}$ of highly purified bovine tubulin by incubation at $35^{\circ} \mathrm{C}$ for $30 \mathrm{~min}$ in $\mathrm{PEM}$ buffer supplemented with $1 \mathrm{~mm}$ GTP (Cytoskeleton, Denver, CO). One milligram of COS-7 cell extract was then added to the assembled microtubules, and the mixtures were incubated at $35^{\circ} \mathrm{C}$ for $30 \mathrm{~min}$. The mixtures were then layered on top of $1 \mathrm{ml}$ of cushion buffer, and the polymerized microtubules were sedimented by centrifugation at 100,000 $\times g$ for $40 \mathrm{~min}$ at $35^{\circ} \mathrm{C}$. The supernatant of this original spin was collected, and the microtubule pellets were then subjected to three cycles of cold depolymerization, warm polymerization, and centrifugation. The final purified microtubule pellet, the concentrated supernatant, and an aliquot of the initial cytosol were then analyzed by Western blot analysis for the presence of the recombinant RP1 proteins using anti-V5 antibodies.

Microtubule polymerization assay. To generate purified recombinant Rp1 proteins for use in microtubule polymerization assays, $7.5 \times 10^{6}$ HeLa cells were transfected with $30 \mu \mathrm{g}$ of plasmid DNA. The transfected
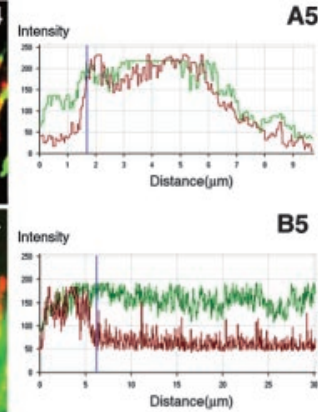

cells were cultured in F-12K media with $10 \%$ FCS for $3 \mathrm{~d}$. The His-tagged recombinant proteins were then purified from cell extracts using Talon Metal Affinity Resin (Clontech, Palo Alto, CA) according to the manufacturer's instructions. The purified proteins were dialyzed overnight against PEM buffer at $4^{\circ} \mathrm{C}$ and concentrated to $1 \mathrm{mg} / \mathrm{ml}$ using a Centricon spin concentrator (Amicon, Beverly, MA). SDSPAGE analysis of the purified recombinant proteins demonstrated that they were $\geq 90 \%$ pure.

For polymerization assays, purified bovine tubulin (Cytoskeleton) was diluted to $10 \mu \mathrm{M}$ in $200 \mu \mathrm{l}$ PEM buffer with $1 \mathrm{~mm}$ GTP in a quartz cuvette. The purified recombinant N1- or N2RP1 proteins were then added to the cuvettes to a final concentration of $5 \mu \mathrm{M}$ and mixed briefly, and the assembly of tubulin into microtubules was followed by measuring the absorbance of the solutions at $340 \mathrm{~nm}$ at $1 \mathrm{~min}$ intervals in a Beckman DU 640 spectrophotometer equipped with temperature-controlled cells (Gaskin, 1982). Switching the temperature to $37^{\circ} \mathrm{C}$ induced assembly. The initial absorbance was set to zero at time 0 for each sample. PEM buffer was used as negative control, and $10 \mu \mathrm{M}$ Taxol was used as a positive polymerization control.

\section{Results}

\section{Rp1 is concentrated in the outer} segment portion of the photoreceptor axoneme

The RP1 protein was localized previously to the region of the connecting cilia of rod and cone photoreceptors (Liu et al., 2002). To determine whether RP1 is part of the photoreceptor axoneme, we performed colocalization studies with antibodies to acetylated $\alpha$-tubulin that bind only to stabilized microtubules (Sale et al., 1988). We also compared the location of Rp1 with other photoreceptor proteins with well defined distributions using confocal immunomicroscopy. Antibodies to the RPGR were used as a marker for connecting cilia (Hong et al., 2003), and antibodies to Rom1 were used as a marker of outer segment discs (Molday et al., 1987).

As shown in Figure 1, Rp1 colocalizes with the acetylated $\alpha$-tubulin of the axoneme (Fig. 1A). This can be seen well in the merged images, where the red Rp1 and green acetylated $\alpha$-tubulin signals overlap to produce a yelloworange signal in the axoneme (Fig. 1A3,A4). The colocalization of the Rp1 and acetylated $\alpha$-tubulin signals was evaluated by quantitative analysis of the immunostaining pattern. For this analysis, the intensity of the different fluorescent labels was evaluated in each pixel along a line drawn through the axoneme using the LSM 510 Meta analysis software. Such an analysis is possible because the Meta detector in the LSM 510 Meta confocal microscope acquires the spectral signatures for each pixel of the scanned image. This information can then be used to separate the overlapping emission signals within each pixel. The resulting separated signal intensities for each dye were plotted as a function of distance. Using this approach, the Rp1 and acetylated $\alpha$-tubulin 


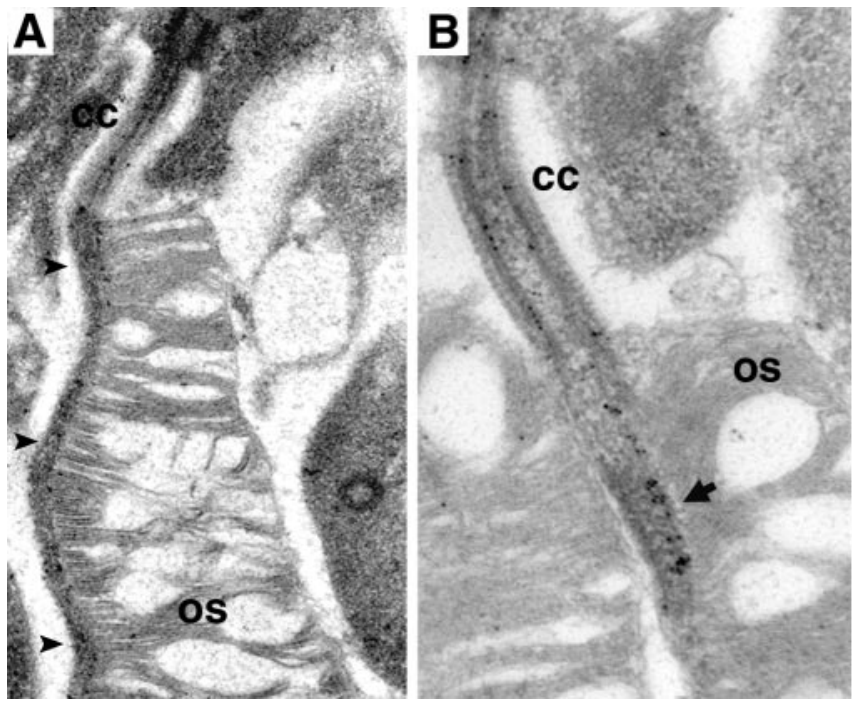

Figure 2. Immunoelectron microscopy of RP1 in the axoneme. Ultrathin sections of mouse retina were probed with anti-C-Rp1 antibodies, followed by gold-conjugated secondary antibodies. A, Lower-magnification image showing that the Rp 1 labeling is located along the length of the axoneme (arrowheads), in both the connecting cilium (CC) and outer segment (OS). $B$, Higher-magnification image showing that $R p 1$ is concentrated in the outer segment portion of the axoneme, next to the newly formed discs (arrow).

signals clearly overlap almost perfectly (Fig. 1A5). The analysis shown in Figure $1 A 5$ is representative of many such analyses performed on this and other double-labeled retinal sections. The quantitative analyses do show a short region of green (acetylated $\alpha$-tubulin) staining that is not overlapped by the red (Rp1) staining at the proximal end of the axoneme. This short region of green signal, which measures $1.2-1.5 \mu \mathrm{m}$, can also be observed in the higher-magnification view of the confocal image and corresponds to the portion of the axoneme in the connecting cilium, which is stained with antibodies to acetylated $\alpha$-tubulin but not with the anti-Rpl antibodies (Fig. 1A4). Immunostaining of isolated photoreceptor outer segments showed the same result, with the portion of the axoneme in the connecting cilium stained by antibodies to acetylated $\alpha$-tubulin but not Rp1 (Fig. 1D).

Rom1 is an integral component of outer segment discs (Bascom et al., 1992). Comparison of the Rp1 and Rom 1 signals confirms that Rp1 is located in the proximal portion of outer segments (Fig. $1 B$ ). Rp1 was present as a single longitudinal streak of fluorescence along one side of outer segments that arises at the base of the outer segment (OS) and continues part of the way toward the distal end. Quantitative analysis of the merged image shows that the Rp1 signal starts in the same location as the Rom 1 signal, again indicating that Rp1 is concentrated in the outer segment portion of the axoneme (Fig. 1B5). The length of the Rp1 signal, as estimated from analyses of $>30$ outer segments, is $8.31 \pm 1.03 \mu \mathrm{m}$. This is approximately one/third of the outer segment length $(25-30 \mu \mathrm{m})$, as measured from the Rom 1 signal.

RPGR and RPGRIP are located in the connecting cilium of rod and cone photoreceptors in mice. Although these proteins have been found in the outer segments of rods and cones in bovine and human retinas, reproducible staining of connecting cilia in mouse retina is obtained when samples are prepared without fixation (Hong et al., 2001, 2003; Mavlyutov et al., 2002). Coimmunostaining shows that the Rp1 and RPGR signals are in distinct portions of axoneme, with Rp1 found distally in the outer segment and RPGR found proximally in the connecting cilium (Fig. 1C). The higher-magnification image and quantitative anal-
A

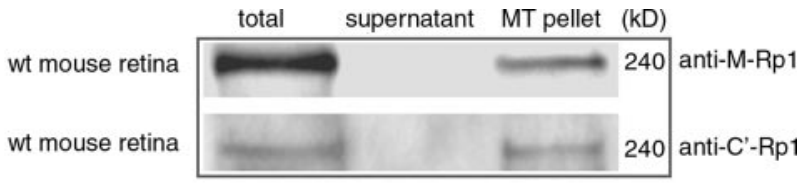

B

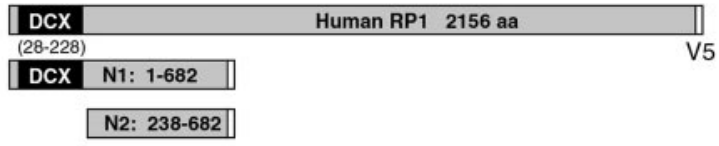

M: 704-1812

C: $1788-2156$

C

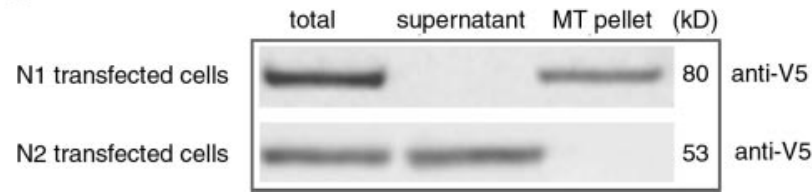

Figure 3. Rp1 coassembles with microtubules. A, Microtubules were assembled from cytosolic extracts of mouse retina by repeated cycles of polymerization-depolymerization. The complete cytosol (total), the supernatant of the first spin, and the final microtubule pellet (MT pellet) were analyzed by Western blot analysis using two different anti-Rp1 antibodies, as indicated. The $240 \mathrm{kDa}$ RP1 protein was detected in the microtubule pellet by both antibodies. $B$, Diagram of the full-length RP1 CDNA and four CDNA fragments used for COS-7 transfection experiments. These constructs contain a C-terminal V5 epitope tag to facilitate identification of the recombinant RP1 proteins. The $R P 1$ codons included are indicated within the body of each construct. The DCX domains are indicated in black; the V5 epitope tag is indicated in white. $C$, The ability of recombinant N1-RP1 and N2-RP1 proteins produced in COS-7 cells to bind to microtubules was tested using a cosedimentation assay. The starting material (total), supernatant, and microtubule pellet (MT Pellet) were analyzed by Western blot analysis using anti-V5 antibodies to detect the recombinant RP1 proteins. The sizes of the detected proteins are shown on the right. The N1-RP1 protein $(80 \mathrm{kDa})$, which contains the DCX domains, c0-sediments with the microtubule pellets. The N2-RP1 protein $(53 \mathrm{kDa})$, which lacks the $D C X$ domains, was found in the supernatant.

ysis show that there is a gap of $200-300 \mathrm{~nm}$ between the Rp1 (red) and RPGR (green) signals.

Immunoelectron microscopy confirms that Rp1 is concentrated in the outer segment portion of the photoreceptor axoneme. The Rp1 labeling extends along the length of the axoneme (Fig. 2A). Higher magnification shows that the Rpl signal is closely associated with microtubule doublets and is concentrated on the side of the axoneme closest to the nascent disc membranes (Fig. $2 \mathrm{~B}$ ). In contrast to the confocal data described above, gold particles are observed in the connecting cilium, although at a lower concentration than seen in the outer segment.

\section{RP1 interacts with microtubules}

We next sought to determine whether RP1 interacts with microtubules. To test this, microtubules were assembled from the cytosolic fraction of retinal extracts by repeated cycles of polymerization, depolymerization, and centrifugation and examined for the presence of Rp1. This microtubule preparation is highly purified and contains only microtubules and MAPs (Sloboda and Rosenbaum, 1982). The starting cytosol, the supernatant from the first round of sedimentation, and the final microtubule pellet were then evaluated for the presence of Rp1 by Western blot analysis. As shown in Figure $3 A$, endogenous Rp1 was associated with the polymerized microtubule pellet. These data suggest that RP1 physically interacts with the microtubule cytoskeleton, either through a direct interaction with microtubules or indirectly through a bridging protein partner. 

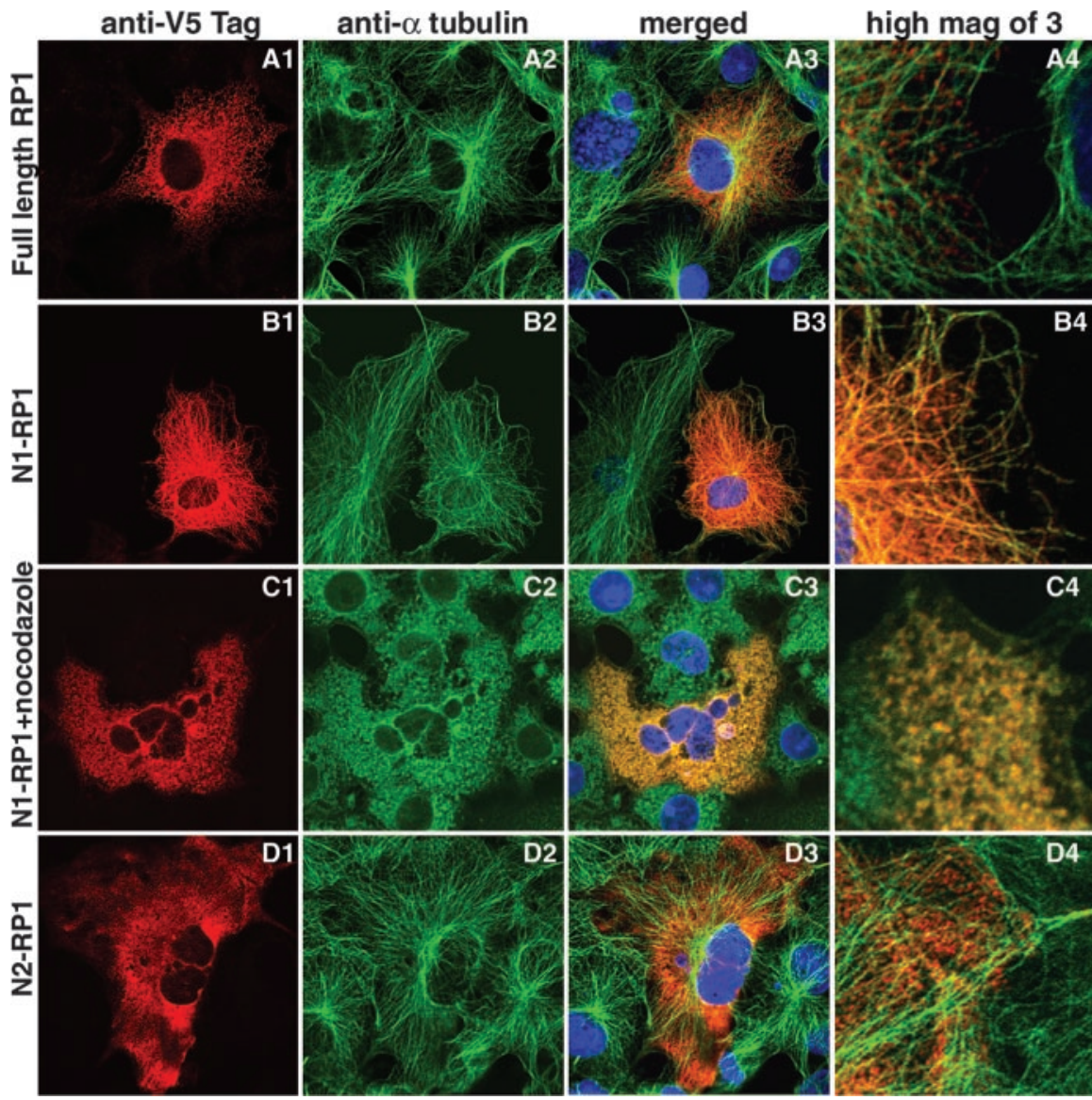

Figure 4. The DCX domains in RP1 are active. The RP1 CDNA constructs indicated on the left were transfected into COS-7 cells, and the cells were coimmunostained with anti-V5 antibodies to detect the recombinant RP1 proteins ( $A 1-D 1$, red) and antibodies to $\alpha$-tubulin to detect the microtubule cytoskeleton (A2-D2, green). Merged images are shown in column 3. Highermagnification views from the images in column 3 are shown in column $4 . A, B$, The full-length and N1-RP1 proteins colocalize with cytoplasmic microtubules. C, Treatment of cells transfected with the N1-RP1 construct with $20 \mu \mathrm{m}$ nocodazole for $2 \mathrm{hr}$ before immunostaining eliminates the RP1 and microtubule networks. D, The N2-RP1 protein does not colocalize with microtubules but rather is diffuse in the cytoplasm.

\section{The interaction between RP1 and microtubules is mediated by the DCX domains in vitro}

Given the findings that RP1 coassembles with microtubules, we next asked whether the interaction between RP1 and the microtubules of the photoreceptor axoneme is mediated by the two tandem DCX domains at the $\mathrm{N}$ terminus of RP1. We prepared five different $R P 1$ constructs that contained different portions of the RP1 cDNA for these experiments (Fig. 3B). The N1-RP1 construct is identical to the Rp1-myc allele; both mimic the truncation alleles that have been found to cause RP1 disease (Berson et al., 2001; Liu et al., 2003). The N2-RP1 construct is a shortened version of the Rp1- $\Delta 2-3$ allele and lacks the DCX domains (Gao et al., 2002). As a first test of the DCX domains, we transfected COS-7 cells with the N1- and N2-RP1 constructs and tested the ability of the two recombinant proteins to bind to polymerized microtubules. As shown in Figure 3C, the N1 protein bound to and sedimented with microtubules. In contrast, the N2-RP1 protein lost its ability to bind to microtubules and was found in the supernatant.

The five RP1 cDNA constructs were then transfected into COS-7 cells, and the cells were coimmunostained with antibodies to $\alpha$-tubulin to detect microtubules and with anti-V5 antibodies to detect the recombinant RP1 proteins. Expression of the fulllength protein was detected, but in fewer cells and at lower levels
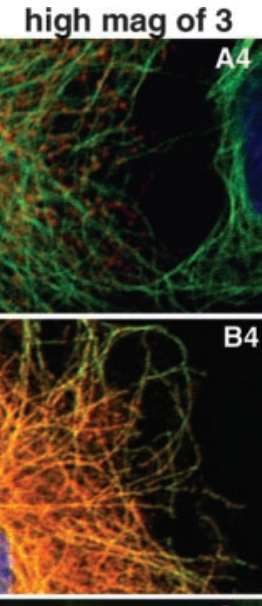

than observed with the shorter constructs. The cells that did express the full-length protein showed a mixed RP1 staining pattern, consisting of a fiber network and punctate spots (Fig. 4A). Comparison of the RP1 and microtubule signals showed that both the RP1 network and spots colocalized with microtubules. This can be seen best in the higher-magnification view of the merged image; each spot of RP1 labeling (red) lines up along a microtubule fiber (green) (Fig. 4A4).

The N1-RP1 protein was also found in an organized network of fibers that extended throughout the cell, with fewer punctate spots of staining than the fulllength protein. Comparison of the N1RP1 and $\alpha$-tubulin signals showed precise colocalization, as indicated by the yelloworange color of the microtubule fibers in the merged images (Fig. 4B). Treatment of the N1-RP1 transfected cells with nocodazole, which depolymerizes microtubules, eliminated both the microtubule and the RP1 networks of staining, indicating that the distribution of RP1 was dependent on the microtubule network (Fig. 4C). Transfection of COS-7 cells with the N2-RP1 protein, which lacks the DCX domains, resulted in diffuse RP1 labeling throughout the cytoplasm that did not match the microtubule network (Fig. 4D). The results for the M- and C-RP1 constructs were identical to those found for N2 (data not shown).

\section{The N1-RP1 protein has MAP activities}

Structural MAPs are defined by their ability to stimulate tubulin polymerization and stabilize polymerized microtubules (Cassimeris and Spittle, 2001). To test the RP1 protein for MAP activities, the stability of microtubules in COS-7 cells transfected with the N1- and N2RP1 constructs was evaluated. Cells were transfected with the N1and N2-RP1 plasmids and then treated with different concentrations of nocodazole $48 \mathrm{hr}$ later. The status of the microtubule networks in the transfected cells was evaluated after $2 \mathrm{hr}$ of nocodazole treatment by coimmunostaining the cells with antibodies to V5 (to detect the recombinant RP1 proteins) and $\alpha$-tubulin. Figure 5 shows that the microtubule network of N1RP1-transfected cells was more resistant to drug-induced depolymerization than the N2-RP1-transfected cells and the surrounding nontransfected cells. For example, in the cultures treated with $5 \mu \mathrm{M}$ nocodazole, 100\% of N1-RP1-transfected cells showed a preserved cytoplasmic microtubule network. In contrast, all of the surrounding nontransfected cells and the N2-RP1-transfected cells lost their cytoplasmic microtubules (Fig. 5A3,B3).

To test the ability of RP1 to stimulate tubulin polymerization into microtubules, recombinant N1- and N2-RP1 proteins were purified from transfected HeLa cell extracts by affinity chromatography. The purified proteins were then tested for their ability to stimulate the polymerization of purified tubulin using a standard in vitro assay (Gaskin, 1982). As shown in Figure 6, the 


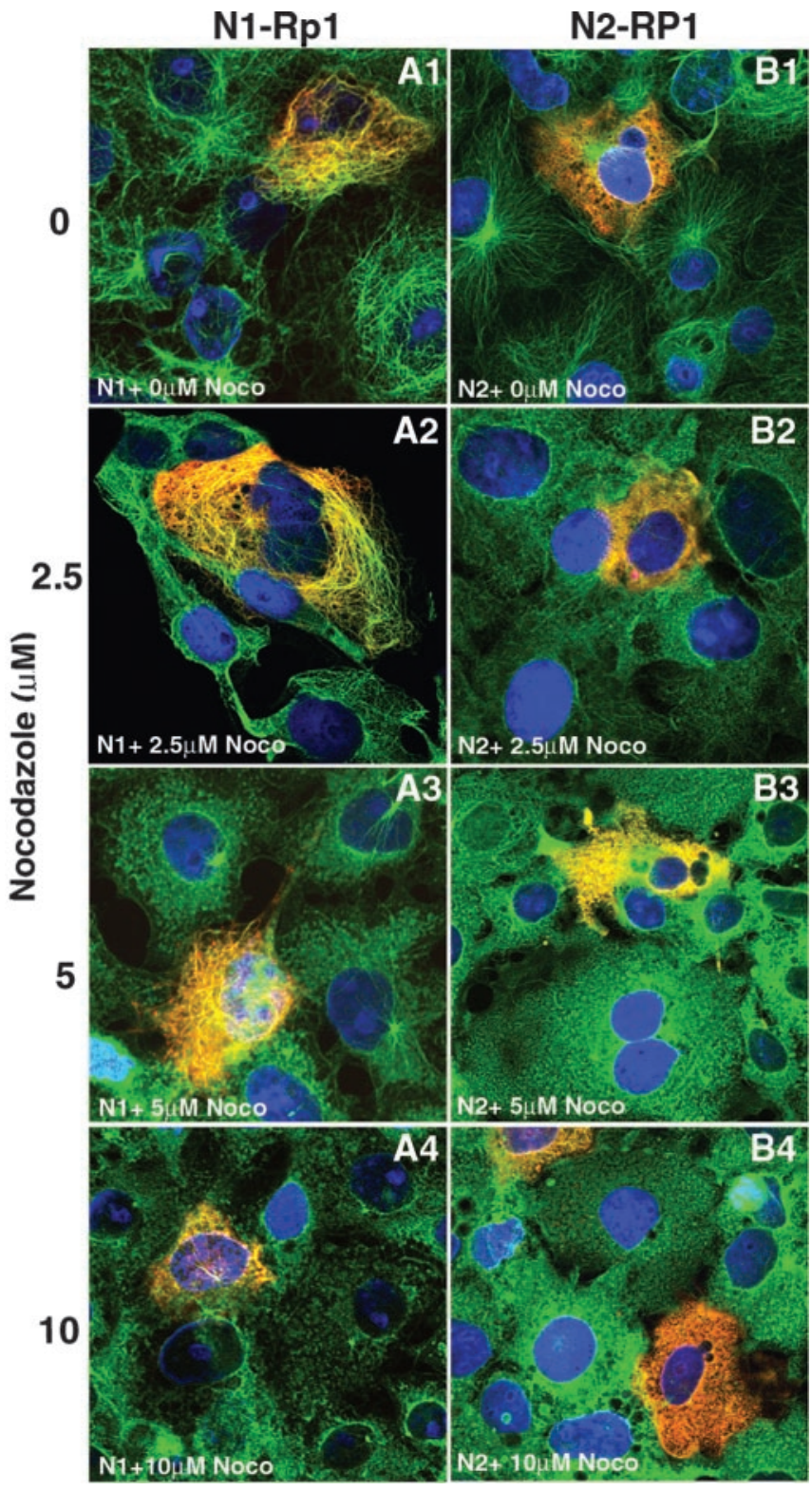

Figure 5. N1-RP1 stabilizes microtubules. Cells transfected with either the N1-RP1 $(A)$ or N2-RP1 (B) CDNA constructs were treated with $0,2.5,5$, or $10 \mu \mathrm{m}$ nocodazole for $2 \mathrm{hr}$, as indicated. The cells were then coimmunostained with anti-V5 (red) and anti- $\alpha$-tubulin (green) antibodies to assess the stability of the microtubule network in transfected cells. Nuclei were counterstained with DAPI (blue). Cells transfected with N1-RP1 retained intact cytoplasmic microtubule networks up to $5 \mu \mathrm{m}$ nocodazole (A1-A3). N2-RP1 did not colocalize with microtubules, and treatment of N2-RP1-transfected cells with all concentrations of nocodazole caused loss of microtubule networks (B1-B4). After treatment with $10 \mu \mathrm{m}$ nocodazole, the cytoplasmic microtubules of the N1-RP1-transfected cells were also partially disrupted, although some polymerized microtubules remained in transfected cells, especially in the microtubule organizing centers. Even the microtubule organizing centers have been lost in the surrounding untransfected cells and N2-RP1-transfected cells subjected to $10 \mu \mathrm{m}$ nocodazole (A4-B4).

N1-RP1 protein greatly enhanced the rate and extent of tubulin polymerization. In contrast, the $\mathrm{N} 2-\mathrm{RP} 1$ protein, which lacks the DCX domain, was a much less potent stimulus of tubulin polymerization. It would be desirable to repeat these in vitro experiments with full-length RP1 protein. Unfortunately, the efficiency of transfection and level of protein expression in cultured cells have been low using the full-length RP1 expression vector, despite repeated attempts using several different promoters and

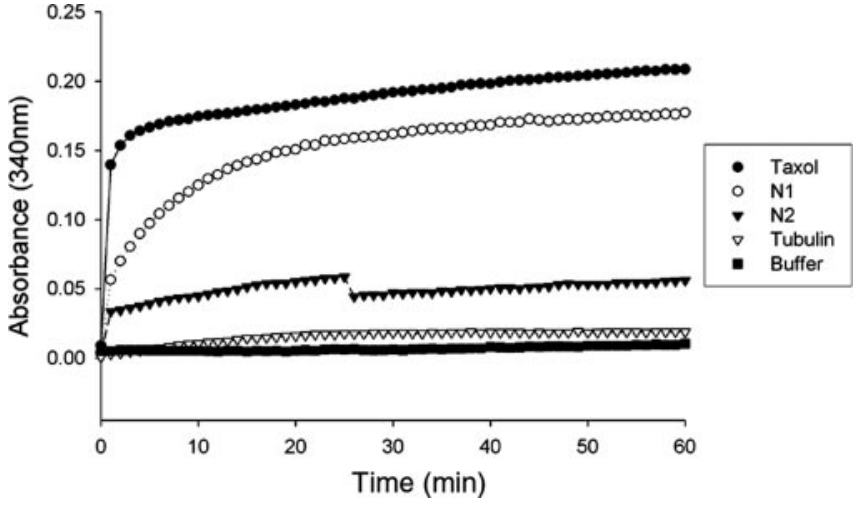

Figure 6. N1-RP1 stimulates microtubule polymerization. N1-RP1 and N2-RP1 recombinant proteins were incubated with purified tubulin at $37^{\circ} \mathrm{C}$, and the extent of polymerization into microtubules was measured by absorbance at $340 \mathrm{~nm}$ over $60 \mathrm{~min}$ at $1 \mathrm{~min}$ intervals. The N1-RP1 protein was almost as efficient as the positive control Taxol at promoting microtubule assembly. In contrast, the N2-RP1 protein was much less active. Tubulin alone served as a negative control.

transfection systems. We are working on alternative approaches to express the full-length protein.

It is noteworthy that the DCX domains in RP1 are active, although there is only $31 \%$ identity over the 201 amino acid region of homology between RP1 and doublecortin (Pierce et al., 1999). Although other proteins with DCX domains have been demonstrated to be MAPs, they share greater homology with doublecortin. For example, the zyg- 8 protein from Caenorhabditis elegans has been shown to be a DCX MAP that is required for correct mitotic spindle positioning; the zyg-8 DCX domains are $48 \%$ homologous to human doublecortin (Gonczy et al., 2001). These data imply that although the sequence homology is low, the DCX domains of RP1 share the same microtubule-binding ubiquitin fold found in doublecortin and doublecortin-like kinase (DCLK) (Kim et al., 2003).

\section{The DCX domains in the Rp1 protein are active in vivo}

To determine whether the doublecortin domains in RP1 are active in vivo, we took advantage of the two lines of mice with targeted disruptions of the $R p 1$ gene that have been generated to date. Because the Rp1- $\Delta 2-3$ protein lacks the DCX domains and the Rp1-myc protein lacks the C-terminal two-thirds of the Rp1 protein, these two mutant alleles provide the opportunity to assess the function of the DCX domains in vivo (Fig. 7A).

As a first test to evaluate the MAP function of RP1 in vivo, we assessed the lengths of the photoreceptor axonemes in wild-type, homozygous $R p 1^{\Delta 2-3 / \Delta 2-3}$, and $R p 1^{m y c / m y c}$ mice. Two methods were used for these experiments. First, we measured the lengths of isolated photoreceptor axonemes. Immunostaining with antibodies to Rp1 and $\alpha$-tubulin demonstrated that these preparations contain both the axoneme from the outer segment and cytoplasmic microtubules from the inner segment of photoreceptors (Fig. 7B). The axonemes stain with antibodies to Rp1; the cytoplasmic microtubules extend above and stain with antibodies to rootletin (data not shown) (Yang et al., 2002). Ten axonemes isolated from each of the three different types of mice were identified by immunostaining, and their cord lengths were measured from the DIC images. The axonemes of $R p 1^{\Delta 2-3 / \Delta 2-3}$ mice were notably shorter $(3.3 \pm 1.1 \mu \mathrm{m})$ than those isolated from wildtype $(10.1 \pm 1.7 \mu \mathrm{m})$ or $R p 1^{\text {myc/myc }}(9.3 \pm 1.4 \mu \mathrm{m})$ mice.

As a second approach, axoneme lengths were also evaluated in frozen sections prepared from fixed eyes of wild-type, homozy- 
A

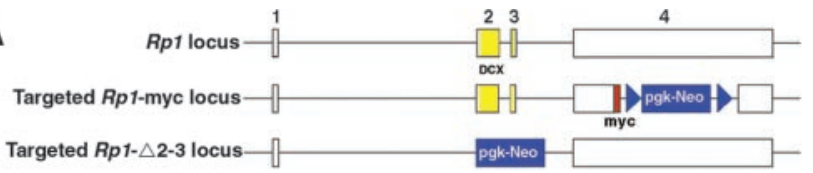

B

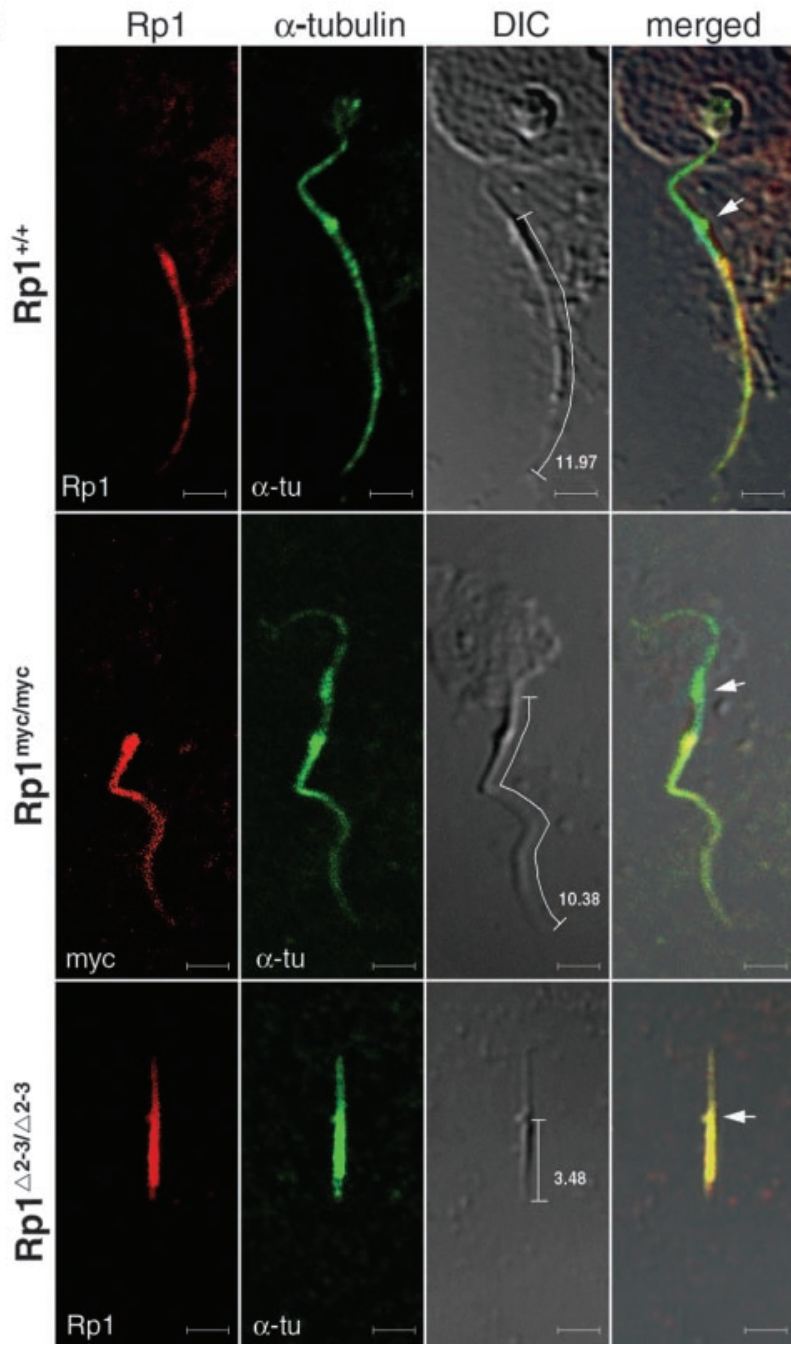

Figure 7. Rp1 proteins with the $D C X$ domains stabilize the photoreceptor axoneme. $A$, The wild-type and targeted Rp 1 loci are depicted. The DCX domains contained in exons 2 and 3 are shown in yellow. The neomycin selection cassettes are shown in blue. The 10 amino acid myctag of the Rp1-myc allele is shown in red. $B$, Photoreceptor axonemes were isolated from the retinas of mice with the genotypes indicated and coimmunostained with antibodies to Rp1 (red) and $\alpha$-tubulin (green). The stained axonemes were then viewed by confocal DIC and fluorescence microscopy. Axonemes from $R p 1^{+/+}$and $R p 7^{m y c / m y c}$ mice were well preserved and measured 11-12 $\mu \mathrm{m}$ from the basal body (arrows) to the distal end. In contrast, axonemes from the $R p^{\Delta 2-3 / \Delta 2-3}$ mice were much shorter, measuring $\sim 3 \mu \mathrm{m}$. The Rp1 signal in the $R p^{\Delta 2-3 / \Delta 2-3}$ axonemes was also mislocalized into the connecting cilium and cytoplasmic microtubules.

gous $R p 1^{\Delta 2-3 / \Delta 2-3}$, and $R p 1^{m y c / m y c}$ mice. Axonemes were identified by staining with antibodies to acetylated $\alpha$-tubulin, followed by confocal immunomicroscopy. The cord lengths of 50 axonemes from each type of mouse were then measured from the stacked three-dimensional confocal images using the LSM510 Meta software. As shown in Figure 8, the axonemes of $R p 1^{\Delta 2-}$ $3 / \Delta 2-3$ mice were significantly shorter $(7.9 \pm 1.3 \mu \mathrm{m})$ than those of wild-type $(9.5 \pm 1.1 \mu \mathrm{m})$ or $R p 1^{\text {myc/myc }}(9.8 \pm 1.3 \mu \mathrm{m})$ mice, although the difference was not as large as that observed in isolated axonemes.

Data from the isolated axonemes suggested that the Rp1- $\Delta 2-3$ protein was mislocalized into the connecting cilium (Fig. $7 B$ ). We therefore examined the location of the Rp1- $\Delta 2-3$ protein in vivo. For these experiments, double mutant $R p 1^{m y c / \Delta 2-3}$ mice with one $R p 1$-myc mutant allele and one Rp1- $\Delta 2-3$ allele were generated by crossing homozygous $R p 1^{\Delta 2-3 / \Delta 2-3}$ and $R p 1^{m y c / m y c}$ mice. The $R p 1^{m y c / \Delta 2-3}$ mice demonstrate the same defects in outer segment formation observed in the mice with the individual mutant alleles, with accumulation of short stacks of enlarged disoriented discs in place of organized outer segments (data not shown) (Gao et al., 2002; Liu et al., 2003). In the retinas of the $R p 1^{m y c / \Delta 2-3}$ mice, the truncated Rp1-myc protein, which contains the DCX domains and has a 10 amino acid $m y c$ tag incorporated at its $\mathrm{C}$ terminus, had almost the same distribution as the wild-type Rp1 protein in the outer segment portion of the photoreceptor axoneme (Fig. 8C1,C3) (Liu et al., 2003). Most of the mutant Rp1$\Delta 2-3$ protein was mislocalized toward the inner segment and overlapped the Rp1-myc signal for only $0.7 \mu \mathrm{m}$ at the base of the outer segment (Fig. 8C1). Coimmunostaining with RPGR showed that the Rp1- $\Delta 2-3$ protein was detected in the connecting cilium and inner segment (Fig. 8C2). This can be appreciated in the quantitative analysis, showing red Rp1- $\Delta 2-3$ signal proximal to, overlapping with, and distal to the blue RPGR signal. A summary of the locations of the different forms of the Rp1 protein is shown in Figure 8D.

\section{Discussion}

RP1 is a MAP that stabilizes the photoreceptor axoneme

The RP1 protein has all the activities of a MAP: it is a component of the photoreceptor axoneme, it coassembles with microtubules from retina, and RP1 proteins that contain the DCX domains can stimulate microtubule polymerization and stabilize existing microtubules in vitro and in vivo. Given the specific expression of RP1 in photoreceptors, RP1 is thus the first photoreceptorspecific MAP to be identified.

The data presented above demonstrate that in vivo RP1 participates in controlling the length and stability of the photoreceptor axoneme and that these MAP activities are mediated primarily by the DCX domains. First, when measured in fixed retinal sections, the axonemes of $R p 1^{\Delta 2-3 / \Delta 2-3}$ mice were $20 \%$ shorter than controls, suggesting that RP1 helps control axoneme length in vivo. Second, axonemes isolated from $R p 1^{\Delta 2-3 / \Delta 2-3}$ mice were $70 \%$ shorter than control axonemes. Because axonemes isolated from wild-type retinas were the same length as that observed in fixed retinal sections, these data are consistent with a role for RP1 in stabilizing the axoneme against the stresses associated with isolation. Furthermore, axonemes from Rp1-myc mice were of normal length, indicating that the N-terminal one-third of RP1 with the DCX domains is sufficient to fulfill the role of RP1 as a stabilizer of the axoneme. The in vitro data support the in vivo findings. Recombinant N1-RP1 protein, containing the same portion of RP1 as the Rp1-myc protein, was able to stimulate polymerization of purified tubulin into microtubules in vitro and to stabilize microtubules in transfected COS-7 cells. The N2-RP1 protein, without the DCX domains, was significantly less active in these assays. The identification of RP1 as a regulator of axoneme length and stability in photoreceptors is significant, given that the axoneme is the first structure produced during the development of, and is thought to be an important organizing structure for, outer segments (De Robertis, 1960).

In other systems, such as Chlamydomonas flagella, axonemes have been shown to be dynamic structures, with continual polymerization and depolymerization of the microtubules at their distal or plus ends (Marshall and Rosenbaum, 2001). The factors 
A

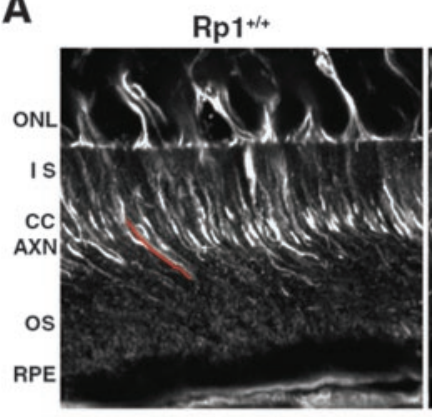

Rp1 1 $^{\text {yyc/myc }}$

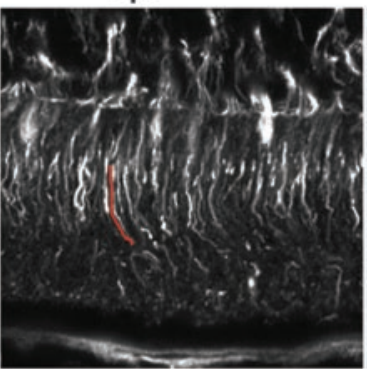

$\operatorname{Rp}^{\Delta 2-3 / \Delta 2-3}$

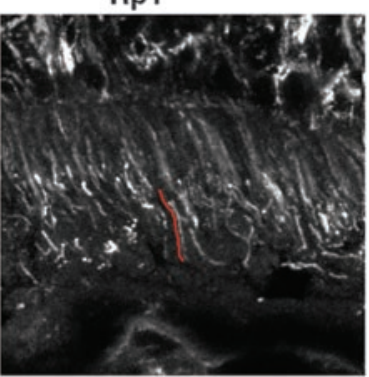

B

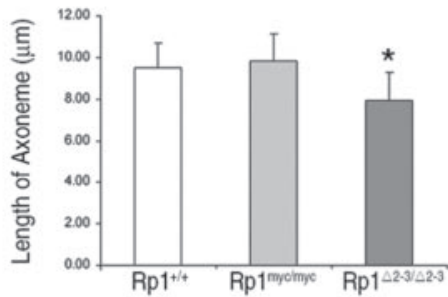

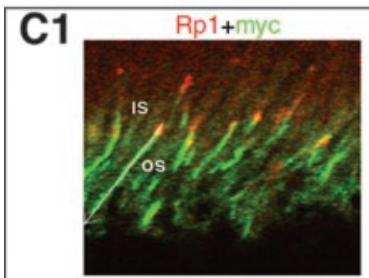

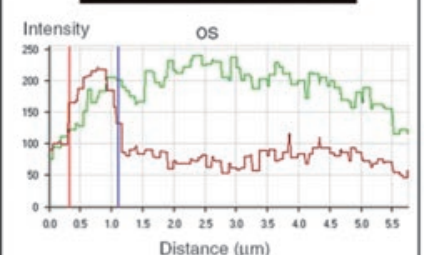

Distance ( $\mu \mathrm{m})$
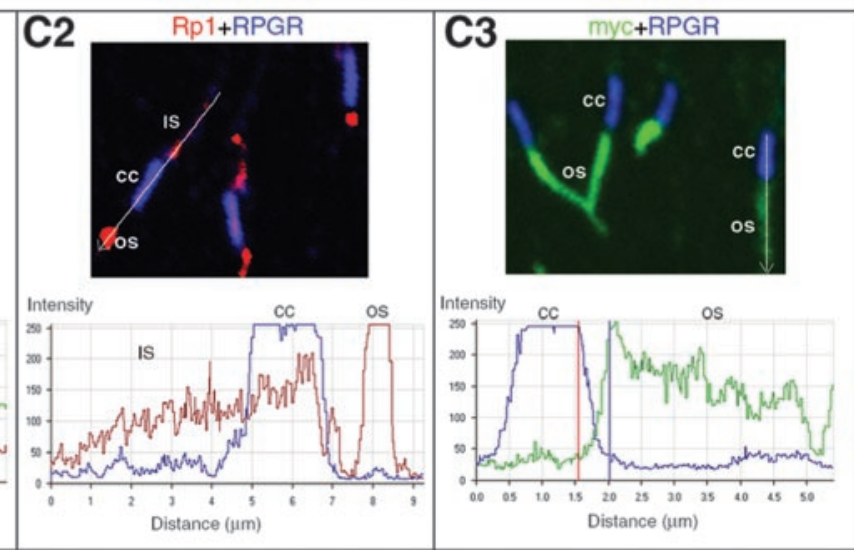

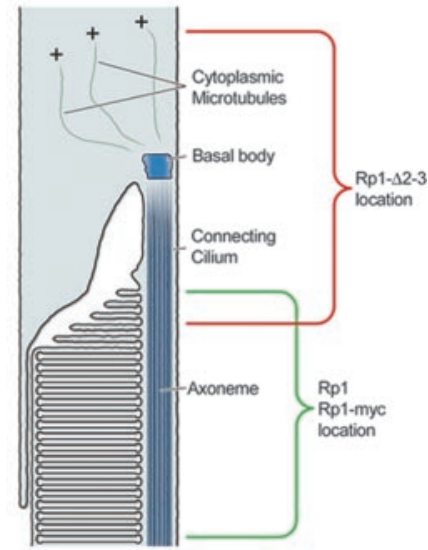

Figure 8. The $D C X$ domains in the Rp1 protein are active in vivo. $A$, Frozen sections of retina from mice with the genotypes indicated were stained with antibodies to acetylated $\alpha$-tubulin and viewed by confocal microscopy. Individual axonemes were identified by viewing the confocal images at high magnification. The axonemes were traced (example traces in red), and the cord lengths of 50 axonemes from each type of mouse were then measured using the LSM510 Meta software. ONL, Outer nuclear layer; IS, inner segment; CC, connecting cilium; AXN, axoneme; OS, outer segment; $R P E$, retinal pigment epithelium. $B$, The mean lengths $\pm S D$ of the 50 axonemes from each genotype of mouse are indicated. The length of the axonemes in the $R p^{\Delta 2-3 / \Delta 2-3}$ mice is significantly shorter than those of the wild-type and Rp1-myc mice $\left({ }^{*} p<0.01\right)$. C, Frozen sections of the retinas from 2-week-old double mutant $R p 1^{m y c / \Delta 2-3}$ mice were coimmunostained with pairs of antibodies to detect the Rp1- $\Delta 2-3$ protein (anti-C-Rp1, red), the Rp1-myc protein (anti-myc, green), and the connecting cilium (anti-RPGR, blue). The merged images and quantitative analyses are shown for each antibody pair. The analysis profiles start proximally and proceed distally into the outer segment. The Rp1-myc protein is localized correctly to the outer segment portion of the axoneme $(C 1,(3)$. In contrast, the Rp1- $\Delta 2-3$ protein is mislocalized into the connecting cilium and inner segment $(C 1, C 2)$. D, Diagram of the junction between the inner and outer segments of a rod photoreceptor cell, showing the location of the wild-type Rp1 and Rp1-myc proteins (green) and the Rp1- $\Delta 2-3$ deletion protein (red).

that control the dynamic equilibrium of axonemes remain to be defined, although it has been demonstrated that axoneme stability in Chlamydomonas is dependent on delivery of axoneme components to the flagellar tip via intraflagellar transport (Qin et al., 2004). The data presented above suggest that the photoreceptor axoneme is also a dynamic structure. RP1 may help regulate the length of the axoneme by promoting rescue (elongation) or suppressing catastrophes (shortening) of the microtubules in the axoneme (Desai and Mitchison, 1997).

There is increasing recognition of the important roles primary or sensory cilia play in many cell types. For example, mutations in the polycystins, which are components of the primary cilia of renal epithelial cells, cause polycystic kidney disease (Calvet and Grantham, 2001). Similarly, mutations in the nephrocystins cause Senior-Loken syndrome, with cystic kidney disease plus retinal degeneration (Hildebrandt et al., 1997; Mollet et al., 2002). Mice with disruption of another cilium protein, polaris or TgN737, also develop defects in right-left symmetry, consistent with a role for cilia in axis patterning during development (Murcia et al., 2000). The finding that a MAP such as RP1 could participate in control of axoneme length and stability may thus be of general importance, because it suggests that other MAPs may also participate in the regulation of axoneme length in other sensory or primary cilia.

\section{RP1 in the outer segment portion of the axoneme}

The immunofluorescence and electron microscopy data show that RP1 is concentrated in the outer segment portion of the axoneme and not the connecting cilium itself. A similar observation was reported recently by Zhao et al. (2003). The connecting cilium of photoreceptors is thought to be analogous to the transition zone of other cilia, in which the triplex structure of the microtubules in the basal body is converted to the duplex structure in the mature axoneme (Rohlich, 1975; Horst et al., 1990; Hong et al., 2003). The outer segment location of RP1 is thus likely to reflect a functional role as part of the mature axoneme, rather than the transition zone within the connecting cilium.

In addition to conferring MAP function to RP1, the DCX domains are also required for correct localization in the outer segment portion of the axoneme; without the DCX domains, the Rp1- $\Delta 2-3$ protein was mislocalized into the connecting cilium and inner segment. These data suggest that other portions of RP1 may also participate in the interaction between RP1 and microtubules, because the truncated Rp1- $\Delta 2-3$ protein was still asso- 
ciated with the axoneme in the connecting cilium. Consistent with this idea, the N2-RP1 protein had limited ability to stimulate tubulin polymerization. The punctate concentrations observed along microtubules after expression of full-length RP1 in COS-7 cells may reflect interactions between the C-terminal portion of RP1 and other proteins within the cell. Punctate staining has also been observed after expression of other MAPs, such as DCX, and MAP2 in cultured cells, so the implications of this expression pattern are not certain (Matus et al., 1986; Gleeson et al., 1999).

\section{RP1 is a MAP neurodegenerative disease}

The importance of MAPs in regulating cell function is highlighted by the findings that MAP dysfunction can lead to several types of neurologic disease. Mutations in doublecortin cause defective neuronal migration during development, leading to the abnormalities in the layering of the cerebral cortex found in the diseases X-linked lissencephaly and double cortex syndrome (des Portes et al., 1998; Gleeson et al., 1998). A mutation in the microtubule-binding domain of the dynactin subunit $\mathrm{p} 150^{\text {Glued }}$ has recently been shown to cause a form of lower motor neuron degeneration (Puls et al., 2003). Mutations in the neuronal MAP tau cause frontotemporal dementia and parkinsonism linked to chromosome 17 (FTDP-17), which is characterized by decreased ability of the mutant tau to bind microtubules, accumulation of tau-containing filaments in neurons, and subsequent neuronal failure (for review, see Garcia and Cleveland, 2001). Similarly, defective tau interactions with axonal microtubules attributable to hyperphosphorylation of tau is an important component in the pathogenesis of Alzheimer's disease (Higuchi et al., 2002). The identification of RP1 as a MAP demonstrates that the RP1 form of RP is part of a larger class of neurodegenerative disorders that are caused by MAP dysfunction.

\section{Does RP1 link outer segment discs to the axoneme?}

Previous data from the $R p 1-\Delta 2-3$ and $R p 1-m y c$ mice indicate that RP1 has a role in keeping newly formed outer segment discs in the correct orientation and in the stacking of discs into mature outer segments (Gao et al., 2002; Liu et al., 2003). How does RP1 accomplish this task? The identification of RP1 as a MAP suggests several possible mechanisms. One possibility is that RP1 is required for formation of the axoneme, which in turn functions to organize outer segment discs (Kaplan et al., 1987). No obvious ultrastructural defects were observed in the axonemes of $R p 1^{\Delta 2-3 / \Delta 2-3}$ and $R p 1^{m y c / m y c}$ mice to support this hypothesis, although additional investigation of this issue is warranted (Gao et al., 2002; Liu et al., 2003). A second possibility is that RP1 could function as a linker protein to help "capture" nascent outer segment discs and align them with the axoneme for stacking and then movement down the outer segment. A class of MAPs called cytoplasmic linker proteins (CLIPs) may perform similar linker functions. CLIP proteins were originally identified by their ability to mediate interactions between microtubules and cytoplasmic organelles. The founding member of the group, CLIP-170, was shown to be required for the binding of endocytic carrier vesicles to microtubules in vitro (Pierre et al., 1992). In addition to their functions as cytoplasmic linkers, some CLIPs are located at the growing (plus) ends of microtubules and regulate microtubule dynamics (Komarova et al., 2002).

It is also possible that RP1 is part of a protein complex that aligns outer segment discs with the axoneme. The dynactin complex may have such a linker function. The dynactin subunit p $150^{\text {Glued }}$ is required for the microtubule-based motility of organelles in neurons (Waterman-Storer et al., 1997). Additional studies showed that microtubules labeled with p $150^{\text {Glued }}$ interact with Golgi membrane vesicles before the transport of the vesicles, suggesting that $\mathrm{p} 150^{\text {Glued }}$ may help capture Golgi membranes for movement (Vaughan et al., 2002). Identification of the other proteins that interact with RP1 will be required to determine whether one of these models is correct.

In either model, with RP1 as a direct link between the discs and axoneme or as a part of a linker complex, the phenotype of Rp1 mutant mice would be explained by loss of the connection between the axoneme and discs. A similar mechanism may be at work in patients with RP1 disease. All 20 RP1 mutations identified to date are either nonsense or frame shift mutations and are clustered at the beginning of exon 4 (codons 263-2156) (Berson et al., 2001). We recently reported that mutant $R P 1$ mRNA can escape nonsense-mediated mRNA decay, consistent with the location of the premature termination mutations after the final intron-exon boundary of the RP1 gene (Liu et al., 2003). Production of truncated protein by the mutant $R P 1$ alleles would be predicted to cause defects in disc stacking similar to those observed in the mutant mice. The presence of disorganized outer segments would then lead to photoreceptor cell death over time, although the mechanism by which this occurs remains to be determined. Mutations in several other photoreceptor genes also lead to production of disorganized outer segments, including retinal degeneration slow-peripherin and RPGRIP, so this may be a common pathway to photoreceptor cell death (Pierce, 2001; Zhao et al., 2003).

\section{References}

Bascom RA, Manara S, Collins L, Molday RS, Kalnins VI, McInnes RR (1992) Cloning of the cDNA for a novel photoreceptor membrane protein (Rom-1) identifies a disk rim protein family implicated in human retinopathies. Neuron 8:1171-1184.

Berson EL, Grimsby JL, Adams SM, McGee TL, Sweklo E, Pierce EA, Sandberg MA, Dryja TP (2001) Clinical features and mutations in patients with dominant retinitis pigmentosa-1 (RP1). Invest Ophthalmol Vis Sci 42:2217-2224.

Calvet JP, Grantham JJ (2001) The genetics and physiology of polycystic kidney disease. Semin Nephrol 21:107-123.

Cassimeris L, Spittle C (2001) Regulation of microtubule-associated proteins. Int Rev Cytol 210:163-226.

De Robertis E (1960) Some observations on the ultrastructure and morphogenesis of photoreceptors. J Gen Physiol [Suppl] 43:1-13.

Desai A, Mitchison TJ (1997) Microtubule polymerization dynamics. Annu Rev Cell Dev Biol 13:83-117.

des Portes V, Pinard JM, Billuart P, Vinet MC, Koulakoff A, Carrie A, Gelot A, Dupuis E, Motte J, Berwald-Netter Y, Catala M, Kahn A, Beldjord C, Chelly J (1998) A novel CNS gene required for neuronal migration and involved in X-linked subcortical laminar heterotopia and lissencephaly syndrome. Cell 92:51-61.

Francis F, Koulakoff A, Boucher D, Chafey P, Schaar B, Vinet MC, Friocourt G, McDonnell N, Reiner O, Kahn A, McConnell SK, Berwald-Netter Y, Denoulet P, Chelly J (1999) Doublecortin is a developmentally regulated, microtubule-associated protein expressed in migrating and differentiating neurons. Neuron 23:247-256.

Gao J, Cheon K, Nusinowitz S, Liu Q, Bei D, Atkins K, Azimi A, Daiger SP, Farber D, Heckenlively J, Pierce EA, Sullivan L, Zuo J (2002) Progressive photoreceptor degeneration, outer segment dysplasia, and rhodopsin mislocalization in mice with targeted disruption of the retinitis pigmentosa-1 (Rp1) gene. Proc Natl Acad Sci USA 99:5698-5703.

Garcia ML, Cleveland DW (2001) Going new places using an old MAP: tau, microtubules and human neurodegenerative disease. Curr Opin Cell Biol 13:41-48.

Gaskin F (1982) Techniques for the study of microtubule assembly in vitro. Methods Enzymol 85:433-439.

Gleeson JG, Allen KM, Fox JW, Lamperti ED, Berkovic S, Scheffer I, Cooper EC, Dobyns WB, Minnerath SR, Ross ME, Walsh CA (1998) Doublecortin, a brain-specific gene mutated in human X-linked lissencephaly and 
double cortex syndrome, encodes a putative signaling protein. Cell 92:63-72.

Gleeson JG, Lin PT, Flanagan LA, Walsh CA (1999) Doublecortin is a microtubule-associated protein and is expressed widely by migrating neurons. Neuron 23:257-271.

Gonczy P, Bellanger JM, Kirkham M, Pozniakowski A, Baumer K, Phillips JB, Hyman AA (2001) zyg-8, a gene required for spindle positioning in $C$. elegans, encodes a doublecortin-related kinase that promotes microtubule assembly. Dev Cell 1:363-375.

Guillonneau X, Piriev NI, Danciger M, Kozak CA, Cideciyan AV, Jacobson SG, Farber DB (1999) A nonsense mutation in a novel gene is associated with retinitis pigmentosa in a family linked to the RP1 locus. Hum Mol Genet 8:1541-1546.

Higuchi M, Lee VM, Trojanowski JQ (2002) Tau and axonopathy in neurodegenerative disorders. Neuromol Med 2:131-150.

Hildebrandt F, Otto E, Rensing C, Nothwang HG, Vollmer M, Adolphs J, Hanusch H, Brandis M (1997) A novel gene encoding an SH3 domain protein is mutated in nephronophthisis type 1. Nat Genet 17:149-153.

Hong DH, Yue G, Adamian M, Li T (2001) Retinitis pigmentosa GTPase regulator (RPGRr)-interacting protein is stably associated with the photoreceptor ciliary axoneme and anchors RPGR to the connecting cilium. J Biol Chem 276:12091-12099.

Hong DH, Pawlyk B, Sokolov M, Strissel KJ, Yang J, Tulloch B, Wright AF, Arshavsky VY, Li T (2003) RPGR isoforms in photoreceptor connecting cilia and the transitional zone of motile cilia. Invest Ophthalmol Vis Sci 44:2413-2421.

Horst CJ, Johnson LV, Besharse JC (1990) Transmembrane assemblage of the photoreceptor connecting cilium and motile cilium transition zone contain a common immunologic epitope. Cell Motil Cytoskeleton 17:329-344.

Kaplan MW, Iwata RT, Sears RC (1987) Lengths of immunolabeled ciliary microtubules in frog photoreceptor outer segments. Exp Eye Res 44:623-632.

Kim MH, Cierpicki T, Derewenda U, Krowarsch D, Feng Y, Devedjiev Y, Dauter Z, Walsh CA, Otlewski J, Bushweller JH, Derewenda ZS (2003) The DCX-domain tandems of doublecortin and doublecortin-like kinase. Nat Struct Biol 10:324-333.

Komarova YA, Akhmanova AS, Kojima S, Galjart N, Borisy GG (2002) Cytoplasmic linker proteins promote microtubule rescue in vivo. J Cell Biol 159:589-599.

Liu Q, Zhou J, Daiger SP, Farber DB, Heckenlively JR, Smith JE, Sullivan LS, Zuo J, Milam AH, Pierce EA (2002) Identification and subcellular localization of the RP1 protein in human and mouse photoreceptors. Invest Ophthalmol Vis Sci 43:22-32.

Liu Q, Lyubarsky A, Skalet JH, Pugh Jr EN, Pierce EA (2003) RP1 is required for the correct stacking of outer segment discs. Invest Ophthalmol Vis Sci 44:4171-4183.

Marshall WF, Rosenbaum JL (2001) Intraflagellar transport balances continuous turnover of outer doublet microtubules: implications for flagellar length control. J Cell Biol 155:405-414.

Matus A, Bernhardt R, Bodmer R, Alaimo D (1986) Microtubule-associated protein 2 and tubulin are differently distributed in the dendrites of developing neurons. Neuroscience 17:371-389.

Mavlyutov TA, Zhao H, Ferreira PA (2002) Species-specific subcellular localization of RPGR and RPGRIP isoforms: implications for the phenotypic variability of congenital retinopathies among species. Hum Mol Genet 11:1899-1907.

Molday RS, Hicks D, Molday L (1987) Peripherin. A rim-specific mem- brane protein of rod outer segment discs. Invest Ophthalmol Vis Sci 28:50-61.

Mollet G, Salomon R, Gribouval O, Silbermann F, Bacq D, Landthaler G, Milford D, Nayir A, Rizzoni G, Antignac C, Saunier S (2002) The gene mutated in juvenile nephronophthisis type 4 encodes a novel protein that interacts with nephrocystin. Nat Genet 32:300-305.

Murcia NS, Richards WG, Yoder BK, Mucenski ML, Dunlap JR, Woychik RP (2000) The Oak Ridge polycystic kidney (orpk) disease gene is required for left-right axis determination. Development 127:2347-2355.

Pacione LR, Szego MJ, Ikeda S, Nishina PM, McInnes RR (2003) Progress toward understanding the genetic and biochemical mechanisms of inherited photoreceptor degenerations. Annu Rev Neurosci 26:657-700.

Pierce EA (2001) Pathways to photoreceptor cell death in inherited retinal degenerations. BioEssays 23:605-618.

Pierce EA, Quinn T, Meehan T, McGee TL, Berson EL, Dryja TP (1999) Mutations in a gene encoding a new oxygen-regulated photoreceptor protein cause dominant retinitis pigmentosa. Nat Genet 22:248-254.

Pierre P, Scheel J, Rickard JE, Kreis TE (1992) CLIP-170 links endocytic vesicles to microtubules. Cell 70:887-900.

Puls I, Jonnakuty C, LaMonte BH, Holzbaur EL, Tokito M, Mann E, Floeter MK, Bidus K, Drayna D, Oh SJ, Brown Jr RH, Ludlow CL, Fischbeck KH (2003) Mutant dynactin in motor neuron disease. Nat Genet 33:455-456.

Qin H, Diener DR, Geimer S, Cole DG, Rosenbaum JL (2004) Intraflagellar transport (IFT) cargo: IFT transports flagellar precursors to the tip and turnover products to the cell body. J Cell Biol 164:255-266.

RetNet (2004) http://www.sph.uth.tmc.edu/retnet/.

Rohlich P (1975) The sensory cilium of retinal rods is analogous to the transitional zone of motile cilia. Cell Tissue Res 161:421-430.

Sale WS, Besharse JC, Piperno G (1988) Distribution of acetylated alphatubulin in retina and in vitro-assembled microtubules. Cell Motil Cytoskeleton 9:243-253.

Shichi H (1983) Biochemistry of vision. New York: Academic.

Sloboda RD, Rosenbaum JL (1982) Purification and assay of microtubuleassociated proteins (MAPs). Methods Enzymol 85:409-416.

Song L, Dentler WL (2001) Flagellar protein dynamics in chlamydomonas. J Biol Chem 276:29754-29763.

Sullivan LS, Heckenlively JR, Bowne SJ, Zuo J, Hide WA, Gal A, Denton M, Inglehearn CF, Blanton SH, Daiger SP (1999) Mutations in a novel retina-specific gene cause autosomal dominant retinitis pigmentosa. Nat Genet 22:255-259.

Vaughan PS, Miura P, Henderson M, Byrne B, Vaughan KT (2002) A role for regulated binding of p150(Glued) to microtubule plus ends in organelle transport. J Cell Biol 158:305-319.

Waterman-Storer CM, Karki SB, Kuznetsov SA, Tabb JS, Weiss DG, Langford GM, Holzbaur EL (1997) The interaction between cytoplasmic dynein and dynactin is required for fast axonal transport. Proc Natl Acad Sci USA 94:12180-12185.

Weingarten MD, Lockwood AH, Hwo SY, Kirschner MW (1975) A protein factor essential for microtubule assembly. Proc Natl Acad Sci USA $72: 1858-1862$.

Yang J, Liu X, Yue G, Adamian M, Bulgakov O, Li T (2002) Rootletin, a novel coiled-coil protein, is a structural component of the ciliary rootlet. J Cell Biol 159:431-440.

Zhao Y, Hong DH, Pawlyk B, Yue G, Adamian M, Grynberg M, Godzik A, Li $\mathrm{T}$ (2003) The retinitis pigmentosa GTPase regulator (RPGR)interacting protein: subserving RPGR function and participating in disk morphogenesis. Proc Natl Acad Sci USA 100:3965-3970. 